\title{
Biogeographic variation in temperature drives performance of kelp gametophytes during warming
}

\author{
Margaret B. Mohring ${ }^{1, *}$, Thomas Wernberg ${ }^{1,2}$, Jeffrey T. Wright ${ }^{3}$, Sean D. Connell ${ }^{4}$, \\ Bayden D. Russell ${ }^{4}$
}

\author{
${ }^{1}$ School of Plant Biology \& UWA Oceans Institute (M096), The University of Western Australia, 35 Stirling Highway, \\ Crawley, WA 6009, Australia \\ ${ }^{2}$ Australian Institute of Marine Science, 39 Fairway, Crawley, Western Australia 6009, Australia \\ ${ }^{3}$ National Centre for Marine Conservation and Resource Sustainability, Australian Maritime College, \\ University of Tasmania, PO Box 986, Launceston, Tasmania 7250, Australia \\ ${ }^{4}$ Southern Seas Ecology Laboratories, School of Earth and Environmental Sciences, University of Adelaide, \\ South Australia 5005, Australia
}

\begin{abstract}
The capacity for thermal adjustment or adaptation is critical to population persistence in a warming ocean. Understanding such performance across a species' range can give insights into the extent of possible adjustment as well as spatial variation in vulnerability. This study tested the effects of temperature on the density and size of gametophytes of the habitatforming kelp Ecklonia radiata, across its Australian distribution (between $\sim 9^{\circ}$ and $\sim 33^{\circ} \mathrm{S}$ ). Gametophytes from warm, intermediate and cool biogeographic regions were cultured over a temperature gradient from 12 to $26^{\circ} \mathrm{C}$, revealing optimum temperatures of $\sim 18$ to $23^{\circ} \mathrm{C}$-well above current maximum temperatures in parts of the range - and a positive relationship between in situ temperature and thermal optima for performance. Optimum temperatures in warmer regions were more than $1^{\circ} \mathrm{C}$ higher than in cooler regions. Biogeographically, the thermal optima for gametophytes were more strongly linked to long-term temperature characteristics of a region (annual extremes, $3 \mathrm{yr}$ range) than short-term variation (mean for the month prior) in sea temperature. These results document that present-day populations of E. radiata have adjusted their gametophyte thermal sensitivity according to their local environment, and further indicate that these differences are adaptive rather than phenotypic. Collectively, these findings suggest that the scope for thermal adaptation and gametophyte performance of E. radiata across most of its Australian distribution is within projected levels of future warming.
\end{abstract}

KEY WORDS: Adaptation · Ecotype $\cdot$ Growth $\cdot$ Ocean warming $\cdot$ Survival $\cdot$ Thermal optima Resale or republication not permitted without written consent of the publisher

\section{INTRODUCTION}

Species with broad geographical distributions, extending across multiple latitudes, commonly span large temperature gradients. In order to survive and optimise performance across their range, these species must adjust their physiology to local conditions and temperature regimes (Sunday et al. 2012). Therefore, thermal optima and latitudinal range of organisms are often directly linked (Somero 2005,
Oppliger et al. 2012, Sunday et al. 2012, Smale \& Wernberg 2013). Thus, biogeographic-scale comparisons of temperature responses enable tests of adaptation beyond experimental observations (Brown et al. 1996, Ladah \& Zertuche-González 2007, Sorte et al. 2011) and can inform on the capability of species to adjust their physiology to changing environmental conditions (Brown et al. 1996, Somero 2005). Any increase in temperature resulting from global climate change is likely to threaten marginal populations, 
that exist at the distributional limits of a species (Somero 2005, Harley et al. 2006, Wernberg et al. 2013). In most cases, the geographic distributions of species are expected to shift poleward, following rising temperatures (Walther et al. 2002). Organisms that cannot shift to a more suitable climate are physiologically susceptible to the effects of increased temperature, such as increased metabolic rates, cellular damage, limited nutrient uptake, photosynthetic inhibition, respiratory distress, reduced growth and productivity, delayed development, and eventually mortality (Davison \& Pearson 1996, Harley et al. 2012).

Susceptibility to temperature stress is dependent on the life-history of the individual (Schiel \& Foster 2006, Matson \& Edwards 2007) and juvenile phases are often more sensitive than adults (Kordas et al. 2011). In intertidal and subtidal marine systems, the life cycle of many species has a planktonic phase, which is particularly susceptible to thermal stress; thus recruitment can be limited by temperature (Lotze \& Worm 2002, Gilman 2006, Harley et al. 2006, Andrews et al. 2014). For example, comparisons of warm and cool climate marine invertebrate populations in both intertidal and shallow subtidal systems revealed differences in densities and a reduction in recruitment over an increasing thermal gradient (Somero 2005, Gilman 2006, Wernberg et al. 2010, Sorte et al. 2011).

Kelps (Order Laminariales) are important foundation species in marine ecosystems and many have broad geographic distributions (Steneck et al. 2002, Bolton 2010). Algae within the order Laminariales have a biphasic, heteromorphic life cycle where the adult, macroscopic sporophyte is diploid and the microscopic gametophytes are haploid (Lüning 1990). There are published observations of variation in thermal tolerances and survival limits of juvenile Laminariales depending on population location; for example, warm water species from Japan are able to tolerate considerably higher temperatures than other species from Arctic regions (tom Dieck 1993). Comparisons of populations Lessonia nigrescens and Ecklonia cava from different points along their distribution revealed that warmer-water inhabitants exhibited greater growth and survival and higher photosynthesis rates at higher temperatures, compared to their cool-water counterparts (Serisawa et al. 2001, Oppliger et al. 2012). Kelp populations under thermal pressure, such as those at the extremes of distribution, exhibit reduced physiological performance, and limited reproduction and recruit survival and growth, resulting in poor popula- tion maintenance and reduced persistence (tom Dieck 1993, Matson \& Edwards 2007, Wernberg et al. 2010, Eggert 2012).

The main habitat-forming macroalga in Australia is the kelp Ecklonia radiata (Wernberg et al. 2003b, Connell \& Irving 2008), which is common in temperate waters around the entire continent. E. radiata beds support fish, invertebrate, and benthic communities (Goodsell et al. 2004, Irving et al. 2004, Wernberg et al. 2006, Vanderklift et al. 2009) many of which are commercially and recreationally important. Despite its ecological significance in Australasia, surprisingly little is known about the effects of temperature on this species, and how this might vary across its wide distribution. Knowledge of the impacts of increasing temperature on the microscopic stages of the life cycle of E. radiata is particularly deficient (Mabin et al. 2013). Therefore, we tested the effect of temperature on the performance of the early life cycle stages of $E$. radiata across the majority of its latitudinal distribution in Australia. By examining the effects of temperature on gametophytes from populations in warm, intermediate and cool climates, this study aimed to assess the variability in thermal optima across the distribution of $E$. radiata and the capacity for thermal adjustment or adaptation of this critical life-cycle stage in this ecologically important species. We hypothesised that populations from different climatic zones would have different thermal optima and that there would be a positive relationship between recent climatic conditions and optimum temperature for gametophyte performance.

\section{METHODS}

\section{Sample collection}

Kelp (Ecklonia radiata) were collected from 3 regions (>1500 $\mathrm{km}$ apart) spanning 2 biogeographic provinces (Heap et al. 2005, Waters et al. 2010) across the latitudinal and longitudinal extent of temperate Australia: Western Australia (WA; 34 16'-38 ${ }^{\circ} 5^{\prime} \mathrm{S}$, $\left.115^{\circ} 00^{\prime}-118^{\circ} 13^{\prime} \mathrm{E}\right)$, South Australia (SA; 35 $17^{\prime}-$ $35^{\circ} 35^{\prime} \mathrm{S}, 137^{\circ} 02^{\prime}-138^{\circ} 39^{\prime} \mathrm{E}$ ) and Tasmania (TAS; $\left.41^{\circ} 51^{\prime}-43^{\circ} 29^{\prime} \mathrm{S}, 146^{\circ} 58^{\prime}-148^{\circ} 19^{\prime} \mathrm{E}\right)$. These regions represent populations in the centre (SA), and at the northern (WA) and southern (TAS) limits of the species' latitudinal range (Fig. 1). In each region, 5 macroscopic kelp thalli were collected from each of 3 sites (1 to $5 \mathrm{~km}$ apart) within each of 3 locations (70 to $250 \mathrm{~km}$ apart). All sites were within a depth range of 


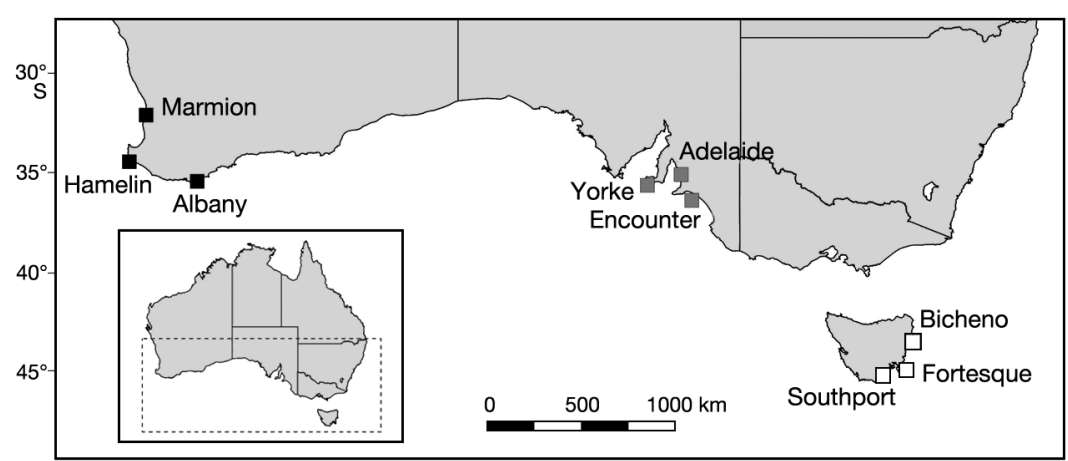

Fig. 1. Ecklonia radiata. Location of the 9 sampling sites in 3 study regions: Western Australia (black symbols), South Australia (grey symbols) and Tasmania (white symbols)

8 to $10 \mathrm{~m}$. Kelps were collected on SCUBA by cutting the stipe just above the holdfast. Thalli were stored in a damp, labelled calico bag that was wrapped in plastic and kept on ice until processing ( 24 h). The 15 thalli from each location were combined into one zoospore source resulting in 3 sets of data from each region. Collections and experiments were carried out in the Austral autumn in May 2011 (WA and TAS) and April 2012 (SA).

After $24 \mathrm{~h}$, a total 150 to $200 \mathrm{~g}$ fresh weight of tissue containing visible sori was trimmed from the 15 combined thalli. For each of the 9 locations, a large plastic container was lined with 56 labelled glass microscope slides $(76 \times 25 \mathrm{~mm}$, thickness $1.2 \mathrm{~mm})$, and filled with 51 of fresh seawater. After desiccating the sporogenic tissue at ambient temperature for $1 \mathrm{~h}$, the tissue was submerged in the container and gently agitated over the following hour in order to promote zoospore release. Slides were left undisturbed for $18 \mathrm{~h}$ to allow settlement before being randomly allocated to their respective temperature treatments. Gametophytes were cultured for a total of $6 \mathrm{~d}$, after which measurements were made, as this culture period is sufficient to determine significant differences in density among temperatures (Mohring et al. 2013a)

\section{Laboratory experiment}

Eighteen small aquaria (volume $\sim 15$ l) were set up in controlled environment rooms, and filled with seawater, and a $250 \mathrm{~W}$ Jager heater was used to heat each tank individually. Aquarium temperatures ranged from 12 to $26^{\circ} \mathrm{C}$, with at least one treatment every $2^{\circ} \mathrm{C}$. Temperature was measured every day using a digital thermometer, and the final treatment temperature was an average of the $6 \mathrm{~d}$ of culture (temperature deviation was $<0.5^{\circ} \mathrm{C}$ over $6 \mathrm{~d})$. Light levels in the controlled environment rooms varied between 5 and 15

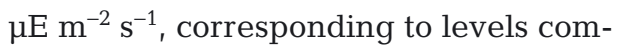
monly encountered at the reef surface in Australasian kelp beds (Novaczek 1984a, Wernberg et al. 2005, Russell 2007). Replicates from all locations were randomly allocated so that all collection locations received similar light treatment overall.

Two small plastic containers (volume $650 \mathrm{ml}$ each), filled with Provasoli Enriched Seawater (PES), were floated on the surface of each aquarium and aerated. PES was used so that thermal performance could be measured under non-limiting conditions, removing any potential influence of differences in nutrient concentrations of locally collected seawater. The enriched seawater was replaced after $3 \mathrm{~d}$ of growth, that is, halfway through the experiment. One microscope slide from each location was randomly allocated to each plastic container (i.e. 2 slides per treatment). The remaining slides $(n=20)$ were used as the initial (Day 1) sample prior to treatment. After $6 \mathrm{~d}$, slides were examined under a compound microscope and 6 random photographs $(0.17 \times 0.13 \mathrm{~mm})$ were taken from each slide, using an eyepiece camera. The number of gametophytes was counted in each photo and was averaged to give one density value (gametophytes $\mathrm{mm}^{-2}$ ) for each replicate/slide. The size (area) of 6 randomly selected gametophytes from each temperature treatment were measured using the ImageJ photo analysis program (Rasband 2009). In the discussion, effects on survival and growth were inferred from density and size results at $6 \mathrm{~d}$, assuming the starting point for all treatments was the same. The optimum temperature for density and size was determined as the mean temperature of treatments yielding the upper tenth percentile of gametophyte densities and sizes. This method is similar to quantile regression but does not require categorical data, and is particularly sensitive to detecting departures from mean conditions (Griffiths \& Willcox 1978, Chen 2012).

In situ temperatures were determined from sea surface temperatures (SST) measured for each location for the month prior to experimentation, as well as the maximum and minimum temperatures during the year prior to sampling (Fig. 2a). The mean difference between the summer maximum and winter minimum temperatures for the 3 years preceding the sample period was also calculated. These time periods for 
integrating temperature measurements were selected to represent a range of time periods over which kelp populations might be affected by local temperatures. SST has been shown to be a good broad proxy for local thermal conditions at 8 to $10 \mathrm{~m}$ depth (Smale \& Wernberg 2009), although peak and absolute temperatures might be under and overestimated, respectively. Temperature data were retrieved from daily SST maps delivered by NOAA and accessed through the Commonwealth Scientific \& Industrial Research Organisation (CSIRO; www. marine.csiro.au/remotesensing/oceancurrents/sst_s/). A single pixel (representing $\sim 20 \times 20 \mathrm{~km}$ ) was selected for each location every day for which temperature data were required and RGB values were converted to SSTs (Smale \& Wernberg 2009). To assess whether thermal optima were related to local patterns of nutrient concentrations and phytoplankton biomass, the temperature responses were also compared to in situ chlorophyll concentrations sourced from NASA Earth observations (http://neo.sci.gsfc.nasa.gov/Search. html). Chlorophyll data were collected from 8 d composite satellite images, processed using the NASA Earth Observations online software, and values were obtained that represented an average concentration for the month prior to sampling, and the maximum and minimum concentrations (Fig. 2b).

\section{Statistical analyses}

Initial (Day 1) densities and sizes of newly settled gametophytes were compared using a 2-factor nested ANOVA to test for differences among regions (fixed factor) and locations (random factor nested within region). Potential effects of differences among regions in initial zoospore settlement densities on the experimental outcome were also tested. This was achieved by averaging the density and size of gametophytes at each location after $6 \mathrm{~d}$ into 3 temperature increments; $<18$, 18 to 22 , and $>22^{\circ} \mathrm{C}$. Regressions were then used to compare the initial densities at each location to the size and density of gametophytes in each of the 3 temperature categories. No density-dependent effects were detected (effect on density: $r^{2}<0.052$, $p>0.05$; effect on size: $\left.r^{2}<0.032, p>0.05\right)$.

Gametophyte density and size after $6 \mathrm{~d}$ of culture was compared between regions and locations, using a General Linear Model Analysis of Covariance, with temperature as a covariate. The optimum temperature for density and size was regressed against the mean SST for the month prior to sampling, mean $3 \mathrm{yr}$ range in $\mathrm{SST}$, and the maximum summer and minimum winter SSTs. Prior to analysis, homogeneity of variances were tested using Cochran's test, which suggested no transformations were required. All analyses were carried out using the statistical software GMAV5 for Windows (Underwood \& Chapman 1998), Sigmaplot (Systat Software 2001) and Minitab (Minitab 2000).
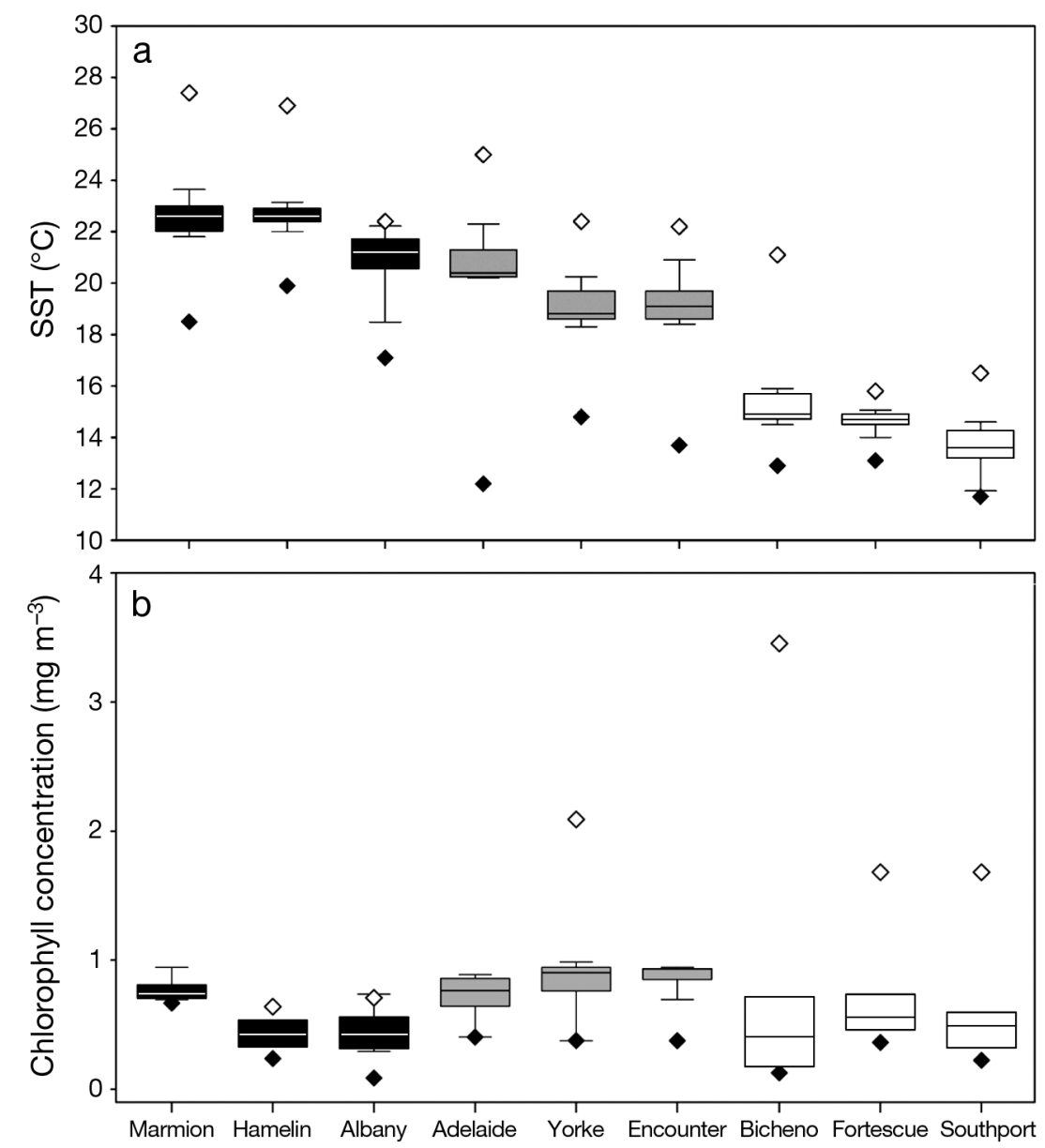

Fig. 2. Ecklonia radiata. (a) In situ sea surface temperature (SST) and (b) chlorophyll concentrations at each location for the $30 \mathrm{~d}$ prior to sampling. Box: median, 25th, and 75th percentiles; whiskers: 10th and 90th percentiles; $(\diamond)$ maximum summer value; $(\diamond)$ minimum winter value 

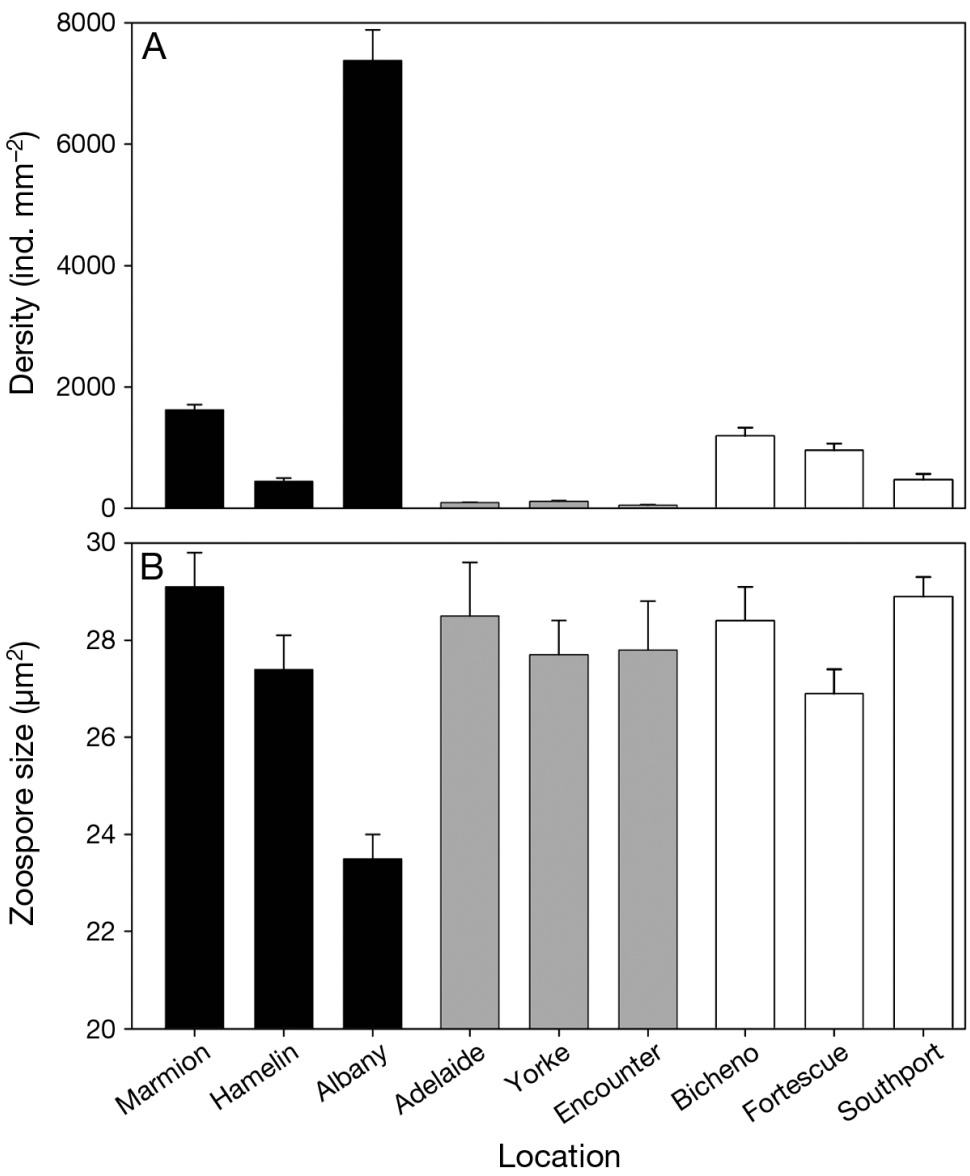

Fig. 3. Ecklonia radiata. (A) Density and (B) size (mean $+\mathrm{SE}, \mathrm{n}=20$ ) of zoospores on experimental slides $18 \mathrm{~h}$ after zoospore release and immediately prior to initiating the temperature treatments for the 3 locations in each region. Black bars: Western Australia; grey: South Australia; white: Tasmania

\section{RESULTS}

\section{Initial settlement densities}

The initial densities of gametophytes settling onto the experimental slides differed significantly among regions $\left(F_{2,177}=40.07, \mathrm{p}<0.001\right)$, with densities from WA 3 to 30 times greater than in TAS and SA (Fig. 3). There were also significant differences among locations within regions $\left(F_{6,171}=159.99, \mathrm{p}<0.001\right)$. Kelp from Albany released by far the most zoospores, with the average density up to 140 times higher than at other locations, and this is likely to have driven the significant difference in density between WA and the other regions. The initial sizes of the gametophytes also differed among regions, although differences were not significant $\left(F_{2,177}=3.01, \mathrm{p}=0.052\right)$, and again there were significant differences in initial size among locations within regions $\left(F_{8,171}=5.42, \mathrm{p}<\right.$
0.001; Fig. 3). Albany differed significantly from all other locations, with smaller initial sizes than recorded elsewhere.

\section{Gametophyte survival and growth}

Gametophyte densities after $6 \mathrm{~d}$ of culture were highly variable over the temperature gradient in all 3 regions (Fig. 4). While there was no significant difference in the density of gametophytes among the regions $\left(F_{(2,321)}=\right.$ $3.71, \mathrm{p}<0.089)$, there was a significant difference among locations within regions $\left(F_{(6,317)}\right.$ $=10.20, \mathrm{p}<0.001)$. The Tasmanian locations showed a distinct peak in gametophyte densities between 18 and $21^{\circ} \mathrm{C}$, with markedly reduced gametophyte numbers in the lowest and highest temperature treatments. Gametophyte density peaked at Adelaide in SA, but no clear peaks were present at the other 2 locations. In general, increasing temperature had a negative effect on gametophyte numbers $\left(F_{1,314}=8.92, \mathrm{p}=0.003\right.$; ANCOVA coefficient -1.39 ). The lowest optimum temperature for gametophyte density was found in Adelaide, where gametophytes performed best at $18.6^{\circ} \mathrm{C}$. Gametophytes from WA had higher temperature optima than the other regions, with gametophytes from Hamelin returning the highest densities at $22.3^{\circ} \mathrm{C}$. At the lower temperatures gametophyte density from WA was constant but began to decline above $15^{\circ} \mathrm{C}$.

Gametophyte size showed distinct peaks between 19 and $21^{\circ} \mathrm{C}$, and most showed a marked decline in the extreme temperature treatments (Fig. 5). Gametophytes from high latitude populations grew larger than those from lower latitude populations, and this was evidenced by a significant difference in gametophyte size among regions $\left(F_{2,962}=46.10, \mathrm{p}<\right.$ $0.001)$ and locations $\left(F_{6,958}=17.85, \mathrm{p}<0.001\right)$. The gametophytes collected from TAS were considerably larger than those from the other regions, and Western Australian gametophytes were the smallest. Overall, increasing temperature had a significant positive effect on the size of gametophytes $\left(F_{1,955}=15.89, \mathrm{p}<0.001 ;\right.$ ANCOVA coefficient 0.02). The highest temperature optimum for size was recorded in WA, at Hamelin, with an optimum of $22.7^{\circ} \mathrm{C}$. The location with the lowest optimal temperature for size was in TAS, at Fortescue, at $20.2^{\circ} \mathrm{C}$ 

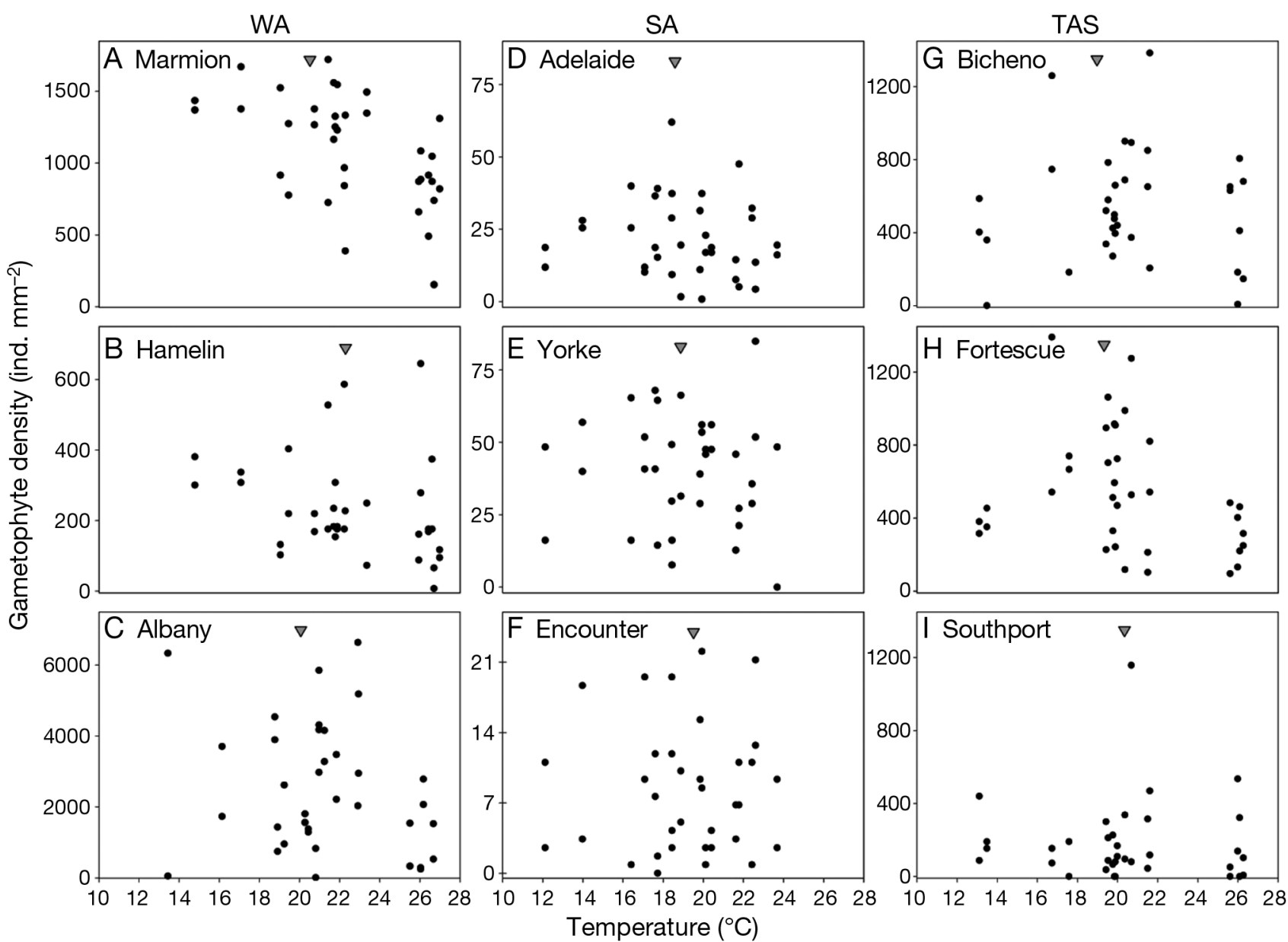

Fig. 4. Ecklonia radiata. Gametophyte density after $6 \mathrm{~d}$ of exposure to various temperatures at locations in Western Australia $\left(W_{i}\right.$ A-C); South Australia (SA; D-F) and Tasmania (TAS; G-I). Each point represents the average density on each replicate slide $(\mathrm{n}=2)$. Note the different scales on the $y$-axes among the locations. $(\nabla)$ Temperature where density is optimal, i.e. the mean temperature of treatments yielding the upper 10th percentile of gametophyte densities

\section{In situ temperature and nutrient characteristics}

Optimum conditions for gametophyte performance were significantly related to all in situ temperature characteristics, except the mean 3 yr temperature range (Table 1, Fig. 6A-C). There was a positive relationship between optimal culture temperature for density and the winter minimum SST $\left(\mathrm{r}^{2}=0.56, \mathrm{p}<0.05\right)$ but no relationship between summer maximum SST and the mean temperature of the preceding month. The significant regression statistics were stronger for comparisons of size $\left(0.58<\mathrm{r}^{2}<0.91\right)$ compared to density $\left(0.12<\mathrm{r}^{2}<\right.$ 0.56). Similar to density, the culture temperatures promoting maximum size were strongly related to in situ winter minimum $\left(\mathrm{r}^{2}=0.91 \mathrm{p}<0.001\right)$. There was also a significant positive relationship between the optimum culture temperature for size and in situ summer maximum $\left(\mathrm{r}^{2}=0.58, \mathrm{p}<0.05\right)$ and the mean SST for the month prior to sampling $\left(\mathrm{r}^{2}=\right.$ 0.62, p < 0.05).

Chlorophyll concentrations (Fig. 2b) prior to sampling were significantly different among the regions $\left(F_{2,177}=8.44, \mathrm{p}=0.001\right)$ and locations $\left(F_{8,171}=3.97, \mathrm{p}=\right.$ $0.002)$. This difference was attributed to the higher chlorophyll values in SA, particularly in Encounter Bay, which returned significantly higher concentrations than Albany, Bicheno and Marmion. Despite the significantly different levels of chlorophyll in the coastal waters at these locations, optimum temperatures for gametophyte density and size could not be significantly $\left(\mathrm{r}^{2}<0.21, \mathrm{p}>0.05\right)$ related to chlorophyll concentrations (Fig. 6D-F). Consequently, thermal optima of gametophytes were not affected by productivity of the ocean waters where kelps were collected. 


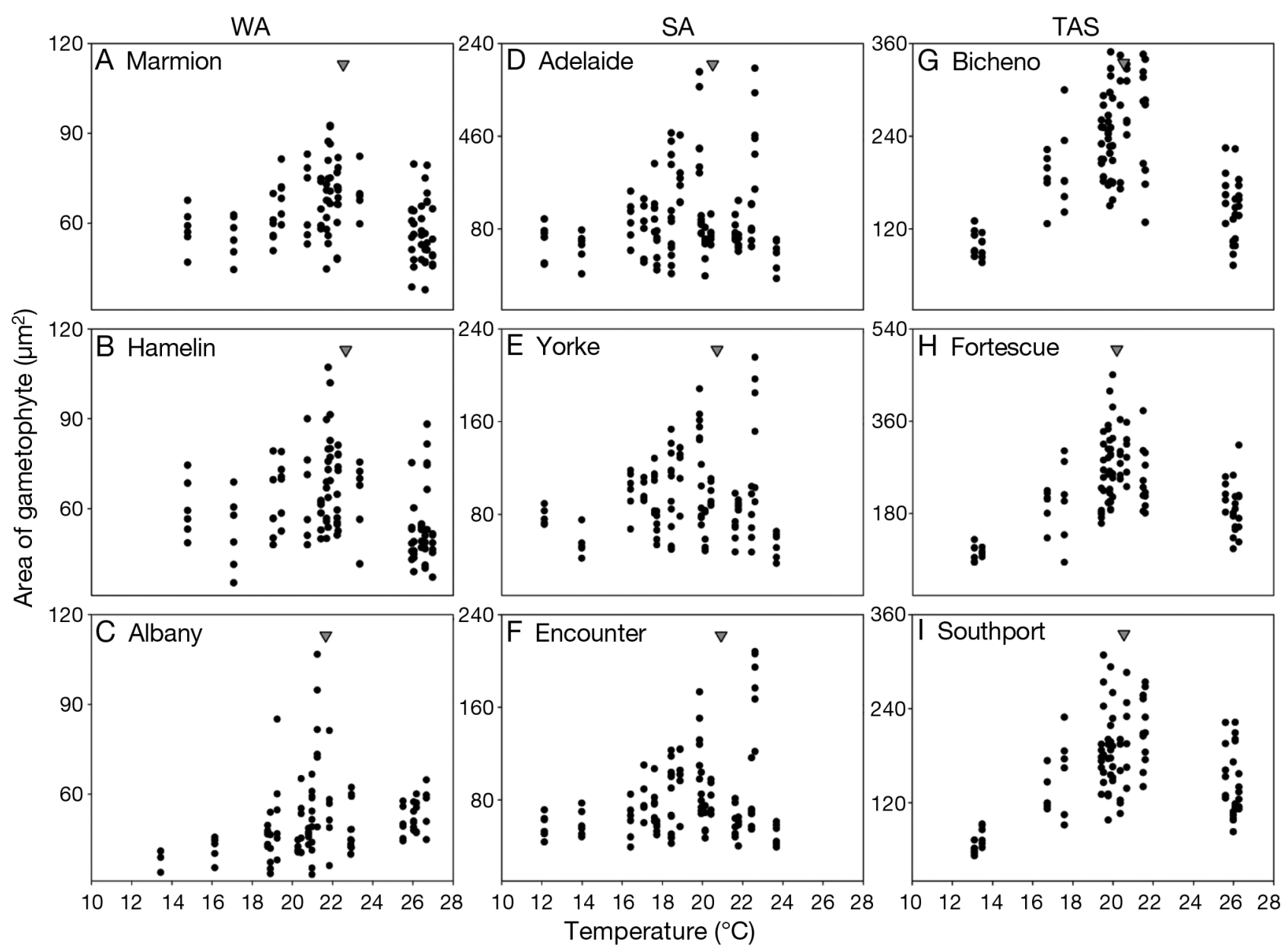

Fig. 5. Ecklonia radiata. Size of gametophytes after $6 \mathrm{~d}$ of exposure to various temperatures at locations in Western Australia $\left(\mathrm{WA}_{;} \mathrm{A}-\mathrm{C}\right)$, South Australia $\left(\mathrm{SA}_{i} \mathrm{D}-\mathrm{F}\right)$; and Tasmania $(\mathrm{TAS} ; \mathrm{G}-\mathrm{I})$. Each point represents a randomly selected gametophyte $(\mathrm{n}=$ $6)_{;}$in some cases $<6$ gametophytes were available for measurement. Note the different scales on the $y$-axes among the locations. $(\nabla)$ Temperature where size is optimal, i.e. the mean temperature of treatments yielding the upper 10th percentile of gametophyte sizes

\section{DISCUSSION}

This study revealed distinct biogeographic patterns in the effects of temperature on the early lifestage performance of kelp populations around temperate Australia. Ecklonia radiata gametophytes had

Table 1 Ecklonia radiata. Results of regression (slope, p-value and regression statistic) of optimum temperature for density and size against in situ temperature characteristics of the locations. Bold: significant

\begin{tabular}{|c|c|c|c|c|c|c|}
\hline \multirow[b]{2}{*}{ Sea surface temp. } & \multicolumn{3}{|c|}{ Density } & \multirow[b]{2}{*}{ Slope } & \multirow{2}{*}{$\begin{array}{c}\text { Size } \\
\mathrm{p}\end{array}$} & \multirow[b]{2}{*}{$\mathrm{r}^{2}$} \\
\hline & Slope & $\mathrm{p}$ & $\mathrm{r}^{2}$ & & & \\
\hline Month prior to sampling & 0.127 & 0.304 & 0.150 & 0.208 & 0.012 & 0.618 \\
\hline Summer max. & 0.097 & 0.362 & 0.120 & 0.172 & 0.017 & 0.581 \\
\hline Winter min. & 0.291 & 0.020 & 0.564 & 0.297 & $<0.001$ & 0.908 \\
\hline Three year annual range & -0.336 & 0.069 & 0.397 & -0.195 & 0.222 & 0.204 \\
\hline
\end{tabular}

optimal survival (density) and growth (size) between 18 and $23^{\circ} \mathrm{C}$, and generally, outside of these temperatures there was a decline in growth and survival. However, gametophyte performance reflected local climatic conditions, as there was a positive relationship between local SST (particularly winter minima) and thermal optima for gametophyte survival and growth. These results not only demonstrate that E. radiata in Australian waters have varied thermal optima for growth and survival, but also that this variability is influenced by biogeography and, furthermore, that Australian kelp populations might exhibit adaptation to local temperature regimes.

The density and morphology of $E$. radiata populations are highly vari- 

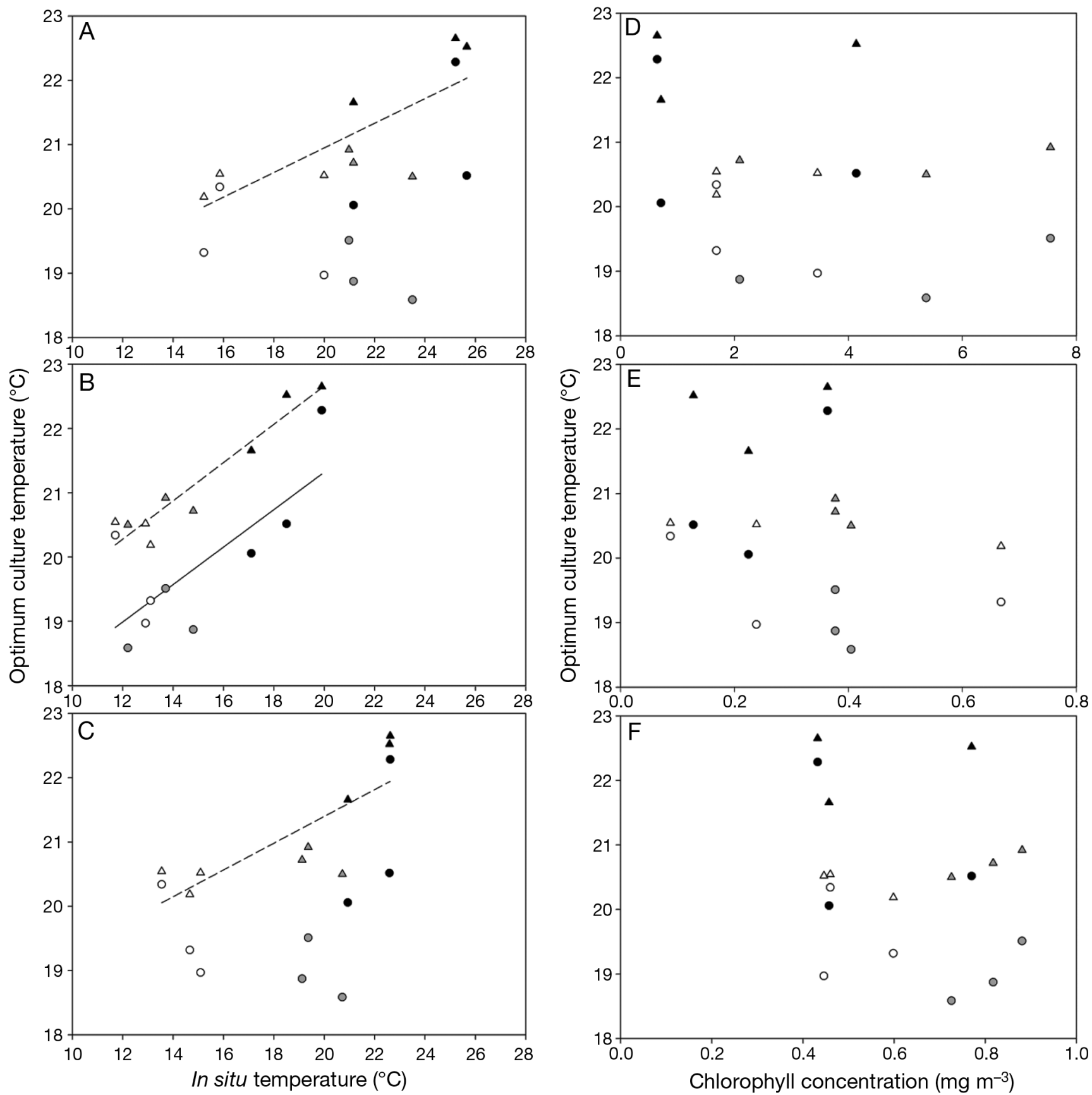

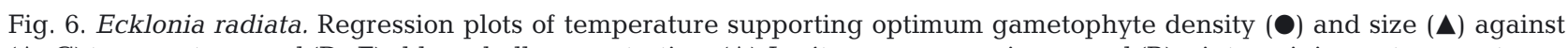
(A-C) temperature, and (D-F) chlorophyll concentration. (A) In situ summer maximum and (B) winter minimum temperatures, and (C) average temperature for the month prior to sampling. (D) In situ maximum, (E) minumum and (F) average chlorophyll concentration for the month prior to sampling. Symbol shades indicate locations in WA (black), SA (grey) and TAS (white).

Solid and dashed lines: significant regressions for density and size, respectively

able across the species' distribution (Wernberg et al. 2003a, Goodsell et al. 2004, Irving et al. 2004, FowlerWalker et al. 2005). This variability has commonly been attributed to local environmental and biological pressures (Wernberg et al. 2003a, Fowler-Walker et al. 2005, 2006, Mabin et al. 2013). There is also a high level of genetic variability among E. radiata populations, even over distances of as small as tens of kilometres, with populations showing genetic divergence due to patterns in boundary currents around the continent (Coleman et al. 2009, 2011). In this study there were distinct differences in the growth of 
gametophytes among regions and even locations. There were also differences in the survival of gametophytes among locations; however, these did not show evidence of a continental-scale pattern. This suggests that Australian populations of E. radiata may differ intrinsically, with differences in gametophyte characteristics reflecting the genetic variation around Australia. For example, densities at the Albany location were anomalous, and were considerably higher than all other locations. This highlights the spatial variability in reproduction occurring among population of this species, but may also be a result of temporal variation. While samples were collected as closely as possible (in time), previous work investigating the reproductive phenology of E. radiata reported significant fluctuations in spore production over time scales of weeks (Mohring et al. 2013b).

Adaptation to local temperature regimes is ecologically important, and is reflected in a range of marine and terrestrial environments (Somero 2005, Sorte et al. 2011). Few studies of Laminariales performance have reported a temperature signature in the ecology of kelp; thus local thermal conditions do not appear to define temperature optima or tolerance ranges of gametophytes. Several studies document no difference in temperature responses between spatially isolated populations, even if they are from differing in situ climate regimes (Bolton \& Lüning 1982, Ladah \& Zertuche-González 2007, Andersen et al. 2013). The effects of temperature on populations of 4 species of Laminaria spp. across the Northern Hemisphere were very similar, with near identical temperature optima for growth despite very different temperature regimes at the collection locations (Bolton \& Lüning 1982). A comparison of 2 populations of Macrocystis pyrifera in California, one from the centre of its distribution and the other near its low latitude extreme, also demonstrated no effect of geographic location on survival of gametophytes from an experimentally simulated ENSO event and the resultant increased temperatures (Ladah \& Zertuche-González 2007). In contrast, there is evidence of differing temperature responses among populations of E. radiata. In New Zealand, gametophytes from warmer-climate populations responded better to increased temperatures than cool-water populations (Novaczek 1984b). Here, there were differences in the thermal optima for survival and growth of gametophytes over various spatial scales, with variation between locations as little as $50 \mathrm{~km}$ apart, extending to differences over the entire distribution of the species. These differences could be linked with in situ temperatures at the locations, suggesting that E. radiata gametophytes have adjusted their thermal characteristics in response to location-specific conditions, rather than having general characteristics across the entire biogeographical range of the species.

In this study, there was a significant relationship between winter minimum at each location and thermal optima with respect to gametophyte survival. However, growth was related to both short-term (average of the month prior to sampling) and longterm (summer maximum and winter minimum) in situ temperature patterns. The relationship between thermal optima and in situ conditions was much stronger for growth than survival, highlighting the fact that growth is a more temperature-sensitive process. Adaption to long-term patterns and trends typically reflects the ability of a population to withstand gradual changes in the system through acclimatization (Somero 2005, Sorte et al. 2011). However, while links to short-term patterns demonstrate a population's the ability to respond to temporary changes in the thermal environment, they do not provide evidence of ability to survive thermal extremes and long-term increases in temperature (Sorte et al. 2011). These ideas, and the fact that growth appeared linked to both short and long-term thermal characteristics of locations, suggest that E. radiata gametophytes have the capacity to withstand short-term thermal fluctuations, and that gradual long-term changes in temperature regimes may result in locally acclimated populations with differing temperature responses.

Where gametophytes are more sensitive to temperature, recruitment can be limited in extreme conditions, and the persistence of kelp populations can be threatened. For some species the gametophyte phase of the life cycle is more sensitive to temperature than the macroscopic sporophytes (Matson \& Edwards 2007). In contrast, Novaczek (1984b) found that $E$. radiata gametophytes in New Zealand could grow at temperatures higher than those at which adults occur. These are not isolated findings. Mabin et al. (2013) found that E. radiata gametophytes could grow in temperatures up to $25^{\circ} \mathrm{C}$ but no sporophytes developed. Gametophytes of several Arctic Laminariales are able to tolerate up to $20^{\circ} \mathrm{C}$, while the sporophytes live in -1.5 to $5^{\circ} \mathrm{C}$; and, while tolerance of adult plants was not tested, it was assumed that they could not tolerate temperatures higher than this. Antarctic species, existing in $<5^{\circ} \mathrm{C}$ water temperature, were able to produce gametophytes that could grow in 13 to $16^{\circ} \mathrm{C}$ (tom Dieck 1993). Similarly, 4 species of Laminaria had sporophyte populations with a temperature optima for growth and survival of 10 to 
$15^{\circ} \mathrm{C}$, while their gametophyte phase grew best between 21 and $23^{\circ} \mathrm{C}$ (Bolton \& Lüning 1982). These authors concluded that the limit of population distribution is determined by upper lethal limits of sporophyte populations rather than the gametophyte phase. In this work, the temperature range that macroscopic sporophytes were subjected to in 2011 $\left(15.8\right.$ to $\left.27.4^{\circ} \mathrm{C}\right)$ was marginally higher than our experimental temperature range. We found that gametophytes were able to survive and grow in all temperature treatments tested $\left(12\right.$ to $\left.26^{\circ} \mathrm{C}\right)$. Without testing a wider range of temperatures, outside those which E. radiata is subjected to in situ, conclusions cannot be drawn regarding which phase of the life cycle controls population persistence.

While the relationship between gametophyte performance and temperature was as expected, some results were unexpected. (1) There was a negative relationship between survival and culture temperature; however, growth was positively related to culture temperature. Since E. radiata exists in water temperatures above the thermal limits for most other species of the Laminariales (tom Dieck 1993), and reproduces when annual water temperatures are the warmest, the conditions for reproduction of this species promote gametophyte growth rather than being favourable for survival (Mohring et al. 2013b). However, gametophytes must still survive, and the gametes must still be viable for populations to persist, so the tolerance level for survival still has the potential to define this species' distribution. (2) The thermal optima for the most southerly populations were higher than temperatures the populations are ever subjected to naturally. So, the thermal optima for gametophyte performance are high relative to the thermal regime of $E$. radiata distribution, such that reproduction occurs when water temperatures are at annual maxima, and in some cases the water temperature never reaches levels high enough to promote optimum performance. This finding suggests that this species may be limited by cool temperatures at the southern end of its distribution. In combination, these findings suggest that cool-water populations can withstand greater increases in sea temperature than those closer to their limits. This also means that the effects of changing climates may differ among regions, since gametophytes from cool-water populations are growing in temperatures below optimum, they may perform better in future climates; while, an increase in sea temperatures will likely cause a decline in performance in warm-water populations.

In conclusion, E. radiata gametophyte performance reflected local climatic conditions as evidenced by a positive relationship between local sea temperature and thermal optima for gametophyte survival and growth. Since variability in thermal optima was controlled by biogeographic position, Australian kelp populations appear to have the capacity to adapt to local temperature regimes and, potentially, to acclimatise to a changing climate. Importantly, cool-water populations of kelp responded better to increased temperature, and may have a greater capacity to tolerate larger increases in sea temperature than those closer to their warm-water limits.

Acknowledgements. This study was supported by the University of Western Australia and the Australian Geographic Society through an Australian Postgraduate Award and an Australian Geographic Seed Grant to M.B.M. Further support was provided by an Australian National Network in Marine Science Springboard Grant to T.W. and J.T.W., while T.W. and S.D.C. were supported by Future Fellows grants from the Australian Research Council. We are grateful for the support and input from Thibaut de Bettignies, Michael Rule, Andrew Irving, Brezo Martínez, Craig Johnson, Gary Kendrick, and also to Mat Vanderklift for the provision of facilities at CSIRO. We also wish to acknowledge the valuable suggestions made by anonymous reviewers, which improved this publication.

\section{LITERATURE CITED}

Andersen GS, Pedersen MF, Nielsen SL (2013) Temperature acclimation and heat tolerance of photosynthesis in Norwegian Saccharina latissima (Laminariales, Phaeophyceae). J Phycol 49:689-700

Andrews S, Bennett S, Wernberg T (2014) Reproductive seasonality and early life temperature sensitivity reflect vulnerability of a seaweed undergoing range reduction. Mar Ecol Prog Ser 495:119-129

Bolton JJ (2010) The biogeography of kelps (Laminariales, Phaeophyceae): a global analysis with new insights from recent advances in molecular phylogenetics. Helgol Mar Res 64:263-269

> Bolton JJ, Lüning K (1982) Optimal growth and maximal survival temperatures of Atlantic Laminaria species (Phaeophyta) in culture. Mar Biol 66:89-94

> Brown JH, Stevens GC, Kaufman DM (1996) The geographic range: Size, shape, boundaries, and internal structure. Annu Rev Ecol Syst 27:597-623

Chen CL (2012) An introduction to quantile regression and the QUANTREG procedure. SAS Institute Inc., Cary, NC

Coleman MA, Gillanders BM, Connell SD (2009) Dispersal and gene flow in the habitat-forming kelp, Ecklonia radiata: relative degrees of isolation across an east-west coastline. Mar Freshw Res 60:802-809

Coleman MA, Roughan M, Macdonald HS, Connell SD, Gillanders BM, Kelaher BP, Steinberg PD (2011) Variation in the strength of continental boundary currents determines continent-wide connectivity in kelp. J Ecol 99:1026-1032

Connell SD, Irving AD (2008) Integrating ecology with biogeography using landscape characteristics: a case study of subtidal habitat across continental Australia. J Biogeogr 35:1608-1621 
Davison IR, Pearson GA (1996) Stress tolerance in intertidal seaweeds. J Phycol 32:197-211

Eggert A (2012) Seaweed responses to temperature. In: Bischof K (ed) Seaweed biology. Springer, Berlin, p 47-66

Fowler-Walker MJ, Connell SD, Gillanders BM (2005) To what extent do geographic and associated environmental variables correlate with kelp morphology across temperate Australia? Mar Freshw Res 56:877-887

Fowler-Walker MJ, Wernberg T, Connell SD (2006) Differences in kelp morphology between wave sheltered and exposed localities: morphologically plastic or fixed traits? Mar Biol 148:755-767

Gilman SE (2006) Life at the edge: an experimental study of a poleward range boundary. Oecologia 148:270-279

Goodsell PJ, Fowler-Walker MJ, Gillanders BM, Connell SD (2004) Variations in the configuration of algae in subtidal forests: implications for invertebrate assemblages. Austral Ecol 29:350-357

Griffiths D, Willcox M (1978) Percentile regression: a parametric approach. J Am Stat Assoc 73:496-498

- Harley CDG, Hughes RA, Hultgren KM, Miner BG and others (2006) The impacts of climate change in coastal marine systems. Ecol Lett 9:228-241

> Harley CDG, Anderson KM, Demes KW, Jorve JP, Kordas RL, Coyle TA, Graham MH (2012) Effects of climate change on global seaweed communities. J Phycol 48: 1064-1078

Heap AD, Harris PT, Hinde A, Woods M (2005) Benthic marine bioregionalisation of Australia's Exclusive Economic Zone. Geoscience Australia, Canberra

> Irving AD, Connell SD, Gillanders BM (2004) Local complexity in patterns of canopy-benthos associations produces regional patterns across temperate Australasia. Mar Biol 144:361-368

> Kordas RL, Harley CDG, O'Connor MI (2011) Community ecology in a warming world: the influence of temperature on interspecific interactions in marine systems. J Exp Mar Biol Ecol 400:218-226

> Ladah LB, Zertuche-González JA (2007) Survival of microscopic stages of a perennial kelp (Macrocystis pyrifera) from the center and the southern extreme of its range in the Northern Hemisphere after exposure to simulated El Niño stress. Mar Biol 152:677-686

> Lotze HK, Worm B (2002) Complex interactions of climatic and ecological controls on macroalgal recruitment. Limnol Oceanogr 47:1734-1741

Lüning K (1990) Seaweeds: their environment, biogeography and ecophysiology. John Wiley and Sons, New York, NY

> Mabin CJT, Gribben PE, Fischer A, Wright JT (2013) Variation in the morphology, reproduction and development of the habitat-forming kelp Ecklonia radiata with changing temperature and nutrients. Mar Ecol Prog Ser 483: $117-131$

- Matson PG, Edwards MS (2007) Effects of ocean temperature on the southern range limits of two understory kelps, Pterygophora californica and Eisenia arborea, at multiple life-stages. Mar Biol 151:1941-1949

Minitab Inc. (2000) MINITAB 13.1. Pennsylvania State University, State College, PA

Mohring MB, Kendrick GA, Wernberg T, Rule MJ, Vanderklift MA (2013a) Environmental influences on kelp performance across the reproductive period: an ecological trade-off between gametophyte survival and growth?
PLoS ONE 8:e65310

> Mohring MB, Wernberg T, Kendrick GA, Rule MJ (2013b) Reproductive synchrony in a habitat-forming kelp and its relationship with environmental conditions. Mar Biol 160:119-126

Novaczek I (1984a) Development and phenology of Ecklonia radiata at two depths in Goat Island Bay, New Zealand. Mar Biol 81:189-197

> Novaczek I (1984b) Response of gametophytes of Ecklonia radiata (Laminariales) to temperature in saturating light. Mar Biol 82:241-245

> Oppliger LV, Correa JA, Engelen AH, Tellier F and others (2012) Temperature effects on gametophyte life-history traits and geographic distribution of two cryptic kelp species. PLoS ONE 7:e39289

Rasband W (2009) ImageJ 1.42q. National Institutes of Health, Bethesda, MD

> Russell BD (2007) Effects of canopy-mediated abrasion and water flow on the early colonisation of turf-forming algae. Mar Freshw Res 58:657-665

Schiel DR, Foster MS (2006) The population biology of large brown seaweeds: ecological consequences of multiphase life histories in dynamic coastal environments. Annu Rev Ecol Evol Syst 37:343-372

Serisawa Y, Yokohama Y, Aruga Y, Tanaka J (2001) Photosynthesis and respiration in bladelets of Ecklonia cava Kjellman (Laminariales, Phaeophyta) in two localities with different temperature conditions. Phycological Res 49:1-11

Smale DA, Wernberg T (2009) Satellite-derived SST data as a proxy for water temperature in nearshore benthic ecology. Mar Ecol Prog Ser 387:27-37

> Smale DA, Wernberg T (2013) Extreme climatic event drives range contraction of a habitat-forming species. Proc Biol Sci 280:20122829

Somero GN (2005) Linking biogeography to physiology: evolutionary and acclimatory adjustments of thermal limits. Front Zool 2:1-9

Sorte CJB, Jones SJ, Miller LP (2011) Geographic variation in temperature tolerance as an indicator of potential population responses to climate change. J Exp Mar Biol Ecol 400:209-217

Steneck RS, Graham MH, Bourque BJ, Corbett D, Erlandson JM, Estes JA, Tegner MJ (2002) Kelp forest ecosystems: biodiversity, stability, resilience and future. Environ Conserv 29:436-459

Sunday JM, Bates AE, Dulvy NK (2012) Thermal tolerance and the global redistribution of animals. Nature Climate Change 2:686-690

Systat Software Inc (2001) SigmaPlot. Systat Software Inc., San Jose, CA

tom Dieck I (1993) Temperature tolerance and survival in darkness of kelp gametophytes (Laminariales, Phaeophyta): ecological and biogeographical implications. Mar Ecol Prog Ser 100:253-264

Underwood AJ, Chapman MG (1998) GMAV5 for WINDOWS. Institute of Marine Ecology, University of Sydney

Vanderklift MA, Lavery PS, Waddington KI (2009) Intensity of herbivory on kelp by fish and sea urchins differs between inshore and offshore reefs. Mar Ecol Prog Ser 376:203-211

> Walther GR, Post E, Convey P, Menzel A and others (2002) Ecological responses to recent climate change. Nature 416:389-395 
Waters JM, Wernberg T, Connell SD, Thomsen MS and others (2010) Australia's marine biogeography revisited: Back to the future? Austral Ecol 35:988-992

Wernberg T, Coleman MA, Fairhead A, Miller SL, Thomsen M (2003a) Morphology of Ecklonia radiata (Phaeophyta: Laminarales) along its geographic distribution in southwestern Australia and Australasia. Mar Biol 143:47-55

- Wernberg T, Kendrick GA, Phillips JC (2003b) Regional differences in kelp-associated algal assemblages found on temperate limestone reefs in southwestern Australia. Divers Distrib 9:427-441

> Wernberg T, Kendrick GA, Toohey BD (2005) Modification of the physical environment by an Ecklonia radiata

Editorial responsibility: Christine Paetzold, Oldendorf/Luhe, Germany
(Laminariales) canopy and implications for associated foliose algae. Aquat Ecol 39:419-430

- Wernberg T, Vanderklift MA, How J, Lavery PS (2006) Export of detached macroalgae from reefs to adjacent seagrass beds. Oecologia 147:692-701

Wernberg T, Thomsen MS, Tuya F, Kendrick GA, Staehr PA, Toohey BD (2010) Decreasing resilience of kelp beds along a latitudinal temperature gradient: potential implications for a warmer future. Ecol Lett 13:685-694

Wernberg T, Smale DA, Tuya F, Thomsen MS and others (2013) An extreme climatic event alters marine ecosystem structure in a global biodiversity hotspot. Nature Climate Change 3:78-82

Submitted: November 25, 2013; Accepted: June 11, 2014 Proofs received from author(s): September 26, 2014 